\title{
Empowering and training front-line providers treating cervical cancer in Haiti: perspective of a gynecologic oncologist's experience with international surgical missions
}

\author{
Nathalie D McKenzie, Orlando, USA; Sarfraz Ahmad, Orlando, USA; Joseph Bernard Jr, Port-au-Prince, Haiti and \\ Vincent DeGennaro Jr, Port-au-Prince, Haiti
}

A direct flight from Orlando, Florida to Port-au-Prince, Haiti lands mid-day on a hot Friday. Dr Nathalie Dauphin McKenzie is taken directly to the charity clinic of Innovating Health International where she meets all 16 of her pre-operative patients and decides who is 'operable'-that is, those who have had a sufficient response to neo-adjuvant chemotherapy to undergo completion radical abdominal hysterectomy. On completion of all surgical cases over the subsequent 48 hours, she will take a flight back to Orlando.

Haiti has among the highest incidence of cervical cancer in Latin America and

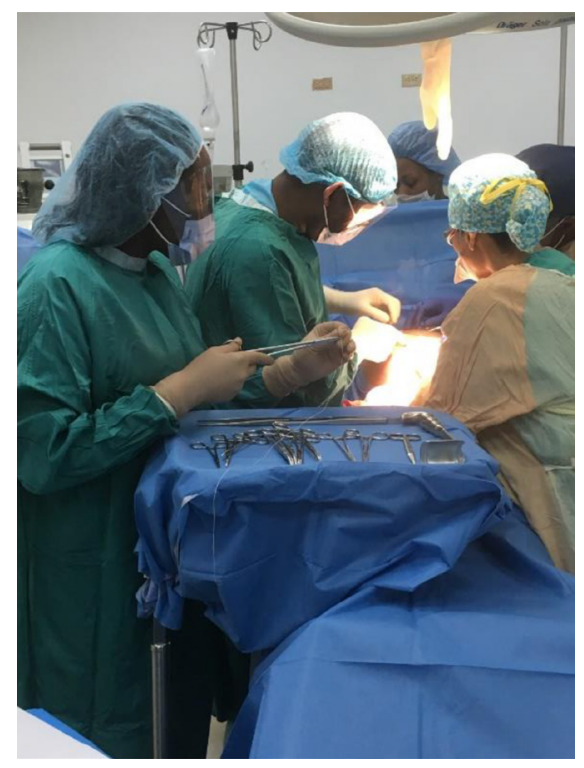

Figure 1 Dr Nathalie D McKenzie of AdventHealth Cancer Institute voluntarily performing radical hysterectomy for a patient with cervical cancer at Port-au-Prince, Haiti, through a charity hospital affiliated with Innovating Health International (surgical mission).

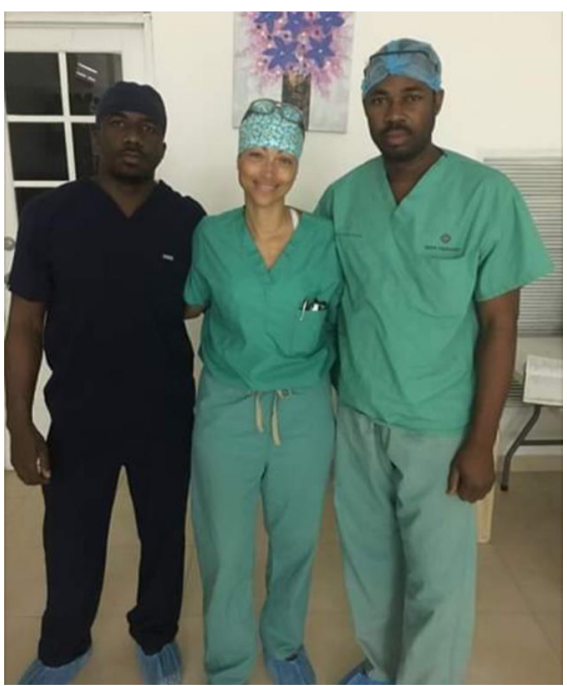

Figure 2 Dr McKenzie (center) with the two local gynecologists she has been training.

the Caribbean and has associated high mortality rates as these women are most commonly diagnosed at advanced stages. Similar to many other under-resourced countries, radiation is not available to the great majority of these women. Their only chance of survival, therefore, is a combination of neo-adjuvant chemotherapy followed by definitive surgical management. ${ }^{1}$ Those with means often seek care outside of the country.

Dr Nathalie D McKenzie, an experienced gynecologic oncologist at AdventHealth Cancer Institute and program director of Gynecologic Oncology Fellowship at AdventHealth Cancer Institute in Orlando, Florida, has been going to a cancer center in Port-au-Prince, Haiti, to perform radical abdominal hysterectomies for these women with cervical cancer. There, she volunteers with a local non-profit organization Innovating Health International. Dr McKenzie's mostly self-funded missions are usually over a weekend with the goal of at least 10 radical abdominal hysterectomies for each mission. Innovating Health International, with limited resources, manages a vertically integrated approach towards cervical cancer treatment combining a widespread screening campaign, awareness program, chemotherapy, and surgery. ${ }^{2}$

There are few, if any, specialty fellowshiptrained gynecologic oncologists in Haiti. Dr McKenzie's mission goals mirror those of Innovating Health International, which are two-fold: (i) to provide life-saving care for women without the financial means to obtain care elsewhere, and (ii) to train at least two local obstetrician/gynecologist physicians to perform complex oncologic surgeries with a goal of independent sustainability without the need for visiting international surgeons . Dr Vincent DeGennaro Jr is the founder of Innovating Health International and the local team is led by $\mathrm{Dr}$ Joseph Bernard Jr (Figure 1).

Specifically, the Innovating Health International team evaluates patients, diagnoses and starts their treatment plan, and follows them up during chemotherapy and after the surgery. Then, volunteer surgeons like Dr McKenzie take turns through self-funded surgical missions providing surgical care for women with advanced cervical cancer. Dr McKenzie has gone to Haiti at least four times, and each time over the course of a weekend performed 7-10 radical abdominal hysterectomies (Figure 2).

About $90 \%$ of all deaths from cervical cancer happen in low-income and middleincome countries. ${ }^{1}$ The etiology is multifactorial; however, lack of radiotherapy, which is reported to benefit $\sim 50 \%$ of all patients with cancer, is most relevant. ${ }^{3}$ The 


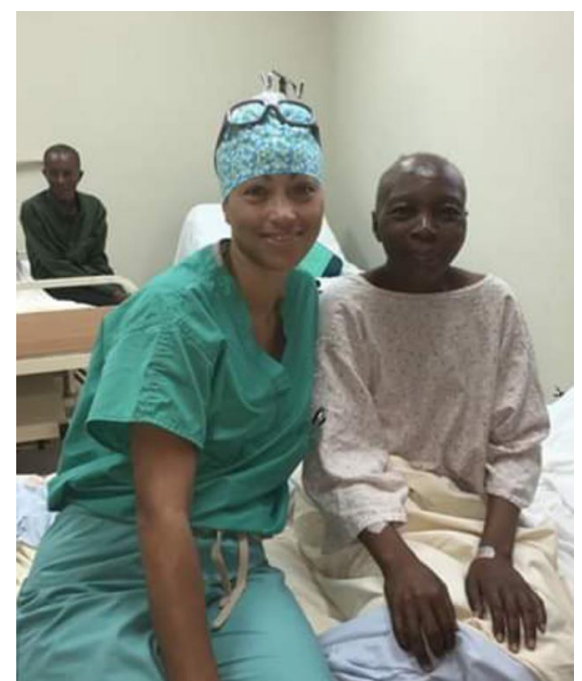

Figure 3 Dr McKenzie (left) with patient after surgery (taken with permission).

care/mortality situation is compounded by limited resources that prohibit Haiti from implementing radiation owing to the lack of proper infrastructure, reliable electricity, optimal security, and geo-political instability. ${ }^{4}$ In accordance with new guidelines for low-resource countries, ${ }^{1}$ Innovating Health International has implemented neo-adjuvant chemotherapy to expand the potential for treating patients with cervical cancer. ${ }^{5} \mathrm{~A}$ recent report has reviewed the screening and treatment methods at Innovating Health International's program using a vertically integrated model. ${ }^{2}$

Dr McKenzie, a breast cancer survivor and fluent in Haitian Creole, describes the limited resources under which clinicians must care for these women. Certainly, the art of medicine, compassion, empathy, and cultural competence are seen in abundance during these missions (Figure 3). At the forefront of these initiatives are volunteer global experts who seek to offer ad hoc medical aid and training of local physicians until nationwide comprehensive programs can be implemented.

Correspondence to Professor Sarfraz Ahmad, Gynecologic Oncology, AdventHealth Cancer Institute, Orlando, FL 32804, USA; sarfraz.ahmad@ AdventHealth.com

Contributors NDM and SA conceived the idea of writing this report and all the authors have contributed to the writing and final approval of this manuscript.

Funding The authors have not declared a specific grant for this research from any funding agency in the public, commercial or not-for-profit sectors.

Competing interests None declared.

Patient consent for publication Not required.
Provenance and peer review Commissioned; internally peer reviewed.

(c) IGCS and ESGO 2020. No commercial re-use. See rights and permissions. Published by BMJ.

D Check for updates

To cite McKenzie ND, Ahmad S, Bernard Jr J, et al. Int J Gynecol Cancer 2020;30:274-275.

Accepted 15 July 2019

Published Online First 26 August 2019

Int J Gynecol Cancer 2020;30:274-275.

doi:10.1136/ijgc-2019-000758

\section{REFERENCES}

1. Chuang LT, Feldman S, Nakisige $C$, et al. Management and care of women with invasive cervical cancer: ASCO resourcestratified clinical practice guideline. $J$ Clin Oncol 2016;34:3354-5.

2. DeGennaro V, Shafer M, Kelly M, et al. Cervical cancer treatment in Haiti: a vertically-integrated model for low-resource settings. Gynecol Oncol Rep 2019;28:71-5.

3. Atun R, Jaffray DA, Barton MB, et al. Expanding global access to radiotherapy. Lancet Oncol 2015;16:1153-86.

4. Barton MB, Jacob S, Shafiq J, et al. Estimating the demand for radiotherapy from the evidence: a review of changes from 2003 to 2012. Radiother Oncol 2014;112:140-4.

5. Gajjar SR, Bernard J, Cantave J, et al. Implementing radiation therapy in Haiti: current status and future directions. Int $J$ Radiat Oncol Biol Phys 2018;102:478-82. 